\title{
Shikonin as an inhibitor of the LPS-induced epithelial-to- mesenchymal transition in human breast cancer cells
}

\author{
DARONG HONG $^{1 *}$, SOON YOUNG JANG ${ }^{2 *}$, EUN HYANG JANG ${ }^{2}$, BOM JUNG $^{2}$, \\ IN-HYE CHO ${ }^{2}$, MIN-JU PARK ${ }^{2}$, SEO YOUNG JEONG ${ }^{1}$ and JONG-HO KIM ${ }^{2}$ \\ Departments of ${ }^{1}$ Life and Nanopharmaceutical Science, and ${ }^{2}$ Pharmacy, Graduate School, \\ Kyung Hee University, Dongdaemun-gu, Seoul 130-701, Republic of Korea
}

Received June 12, 2015; Accepted October 2, 2015

DOI: $10.3892 /$ ijmm.2015.2373

\begin{abstract}
Shikonin (SK), a natural naphthoquinone isolated from the Chinese medicinal herb, has been known to suppress the proliferation of several cancer cells. However, its role in the epithelial mesenchymal transition (EMT) has yet to be demonstrated. The aim of the present study was to examine the effects of SK on EMT. Lipopolysaccharide (LPS) induced EMT-like phenotypic changes, enhancing cell migration and invasion. SK markedly reduced the expression of the LPS-induced EMT markers, including N-cadherin in MDA-MB-231 cells, and increased the expression of E-cadherin in MCF-7 cells. SK also inhibited cell migration and invasion in vitro. The effects of SK on the LPS-induced EMT were mediated by the inactivation of the NF- $\kappa \mathrm{B}-$ Snail signaling pathway. The results provided new evidence that SK suppresses breast cancer cell invasion and migration by inhibiting the EMT. Therefore, SK is a potentially effective anticancer agent for breast tumors, by inhibiting metastasis.
\end{abstract}

\section{Introduction}

Breast cancer ranks among the most common malignant tumors afflicting women worldwide $(1,2)$. Cancer metastasis is the leading cause of mortality in patients with breast cancer, with breast cancer survival rates having decreased from $90 \%$ for localized to $20 \%$ for metastatic disease (3).

Correspondence to: Dr Jong-Ho Kim, Department of Pharmacy, Graduate School, Kyung Hee University, 26 Kyungheedae-ro, Dongdaemun-gu, Seoul 130-701, Republic of Korea

E-mail: jonghokim@khu.ac.kr

Dr Seo Young Jeong, Department of Life and Nanopharmaceutical Science, Graduate School, Kyung Hee University, 26 Kyungheedae-ro, Dongdaemun-gu, Seoul 130-701, Republic of Korea

E-mail: syjeong@khu.ac.kr

*Contributed equally

Key words: shikonin, epithelial-to-mesenchymal transition, migration, invasion, NF- $\mathrm{KB}$-Snail signaling pathway
The prognosis of patients with advanced cancer is associated with the degree of aggressive metastasis $(4,5)$. Thus, elucidation of the mechanisms involved in the metastasis of cancer is imperative as there are limited effective therapies once the cancer has spread. The process of cancer metastasis appears to be regulated by a variety of gene products; however, the precise mechanisms of tumor cell dissemination are poorly understood (6-8). The epithelial-mesenchymal transition (EMT), which has been recognized for several decades as a fundamental process of embryogenesis, may be involved in numerous pathological processes, particularly cancer progression (9). During the EMT of cancer cells in situ, epithelial cell layers lose their polarity and their cell-cell contacts, and then undergo significant remodeling of the cytoskeleton. The expression of proteins such as E-cadherins which promote cellcell contact may be lost, and the cells may acquire $\mathrm{N}$-cadherin which enhances their capacity for cell migration and invasion, and are pivotal events in the initial step of metastasis $(10,11)$. Therefore, investigators have focused on inhibiting the EMT of cancer cells as a new therapeutic strategy to prevent cancer metastasis.

Shikonin (SK) is an active naphthoquinone compound extract derived from the Chinese medicinal herb, Lithospermum erythrorhizon Sieb et Zucc. SK has been reported to exert anti-proliferative and pro-apoptotic effects against various cancer cells via several mechanisms such as inhibition of topoisomerase-I, the regulation of phosphorylation-dependent activities of extracellular-regulated protein kinase, suppression of tumor necrosis factor receptor-associated protein 1 expression, and activation caspases (12-16). In addition, it was previously reported that SK induces the suppression of migration and invasion through the modulation of MMP-9 in human breast cancer cells (17). As previously mentioned, the migration and invasion of cells are associated with EMT for metastasis. In the present study, we hypothesized that SK is an effective inhibitor of EMT during cancer progression, and may therefore be used as an agent for breast tumors. The results showed that, SK significantly inhibited the invasion and migration of MCF-7 and MD-MB231 human breast cancer cells during LPS-induced EMT by downregulating the NF- $\kappa \mathrm{B}-$ Snail signaling pathway. Thus, SK is an excellent candidate agent for use against breast tumors as it inhibits metastasis. 


\section{Materials and methods}

Cell culture and reagents. MDA-MB-231 and MCF-7 cells [all purchased from the American Type Cell Collection (ATCC), Manassas, VA, USA] were maintained in Dulbecco's modified Eagle's medium (DMEM; Gibco, Grand Island, NY, USA) supplemented with $10 \%$ fetal bovine serum (FBS; Gibco) and $1 \%$ penicillin/stereptomycin antibiotics. Shikonin (SK) was purchased from Sigma-Aldrich (St. Louis, MO, USA). The antibodies NF- $\mathrm{KB}$ p65 subunit and $\beta$-actin were purchased from Santa Cruz Biotechnology, Inc. (Santa Cruz, CA, USA), Snail was purchased from Cell Signalling Technology (Beverly, MA, USA), and N- and E-cadherin were purchased from BD Biosciences (San Jose, CA, USA).

Cell proliferation assay. Proliferation assays were based on the 3-[4,5-dimethythiazol-2-yl]-2,5-diphenyl tetrazolium bromide (MTT) method. Cells were seeded at a density of $1 \times 10^{4}$ cells per well in a 96-well plate. After overnight culture, SK $(0.2,0.5$, $1,2,5,10,20$ and $50 \mu \mathrm{M}$ ) was added to the cells and cultured for $24 \mathrm{~h}$. The medium was removed and DMSO (Sigma-Aldrich) was added to the MTT solubilization solution. Absorbance was measured at $550 \mathrm{~nm}$. For the colony-forming assay, single-cell suspensions of $5 \times 10^{3}$ cells were seeded in a 6-well plate and allowed to adhere for $24 \mathrm{~h}$ at $37^{\circ} \mathrm{C}$ in culture medium. The cells were subsequently treated with 5 or $50 \mu \mathrm{M} \mathrm{SK}$. After 10 days, the colonies were fixed with $100 \%$ methanol for $10 \mathrm{~min}$ at room temperature and stained with $0.1 \%$ crystal violet. The plates were washed with PBS (Gibco) and images were captured.

Cell migration assay. Migration was assessed using a wound-healing assay. The cells were seeded at $2 \times 10^{4}$ MDA-MB-231 and MCF-7 cells per well and cultured for $24 \mathrm{~h}$. After scraping the cell monolayer with a sterile micropipette tip (Axygen, Union City, CA, USA), the wells were washed with PBS, and treated with LPS $(5 \mu \mathrm{g} / \mathrm{ml})$ or co-treated with LPS $(5 \mu \mathrm{g} / \mathrm{ml})$ and SK $(5 \mu \mathrm{M})$. The first image of each scratch was obtained at time zero. At $24 \mathrm{~h}$, each scratch was examined and captured at the same location and the healed area was measured.

Transwell invasion assay. The invasion of tumor cells was assessed in Transwell chambers equipped with $8 \mu \mathrm{m}$ pore size, $6.5-\mathrm{mm}$ diameter polyvinylpyrrolidone-free polycarbonated membranes (Corning Costar Inc., Corning, NY, USA) that were coated with $1 \mathrm{mg} / \mathrm{ml}$ fibronectin. The cells were seeded onto the upper wells at a concentration of $1 \times 10^{5}$ MDA-MB-231 and MCF-7 cells/well and were cultured for $24 \mathrm{~h}$ following treatment with LPS $(5 \mu \mathrm{g} / \mathrm{ml})$ or co-treatment with LPS $(5 \mu \mathrm{g} /$ $\mathrm{ml})$ and SK $(5 \mu \mathrm{M})$. The bottom chambers of the Transwell were filled with conditioned medium. After incubation for $24 \mathrm{~h}$, the cells were fixed with $100 \%$ methanol for $10 \mathrm{~min}$ at room temperature, stained with $0.1 \%$ crystal violet and counted under a light microscope.

Western blotting. MDA-MB-231 and MCF-7 cells were treated with with LPS $(5 \mu \mathrm{g} / \mathrm{ml})$ or co-treated with LPS $(5 \mu \mathrm{g} / \mathrm{ml})$ and SK $(5 \mu \mathrm{M})$ for $24 \mathrm{~h}$. After lysing cells with RIPA buffer, the proteins were resolved by SDS-PAGE and immunoblotted using primary antibodies such as mouse monoclonal anti-human-Ncadherin, mouse monoclonal anti-human-E-cadherin, rabbit polyclonal anti-human-NF- $\kappa \mathrm{B}$ p65 subunit, mouse monoclonal anti-human-Snail, and mouse polyclonal anti-human- $\beta$-actin antibody (dilution ratio 1:1,000). Subsequent to treatment with the secondary antibodies (rabbit anti-mouse $\mathrm{IgG}$ and goat anti-rabbit IgG; dilution ratio 1:5,000), the immunoreactive bands were visualized using the standard ECL method.

Immunofluorescent staining. MDA-MB-231 and MCF-7 cells were grown in 4-chamber slides in serum-free media, and were treated with LPS $(5 \mu \mathrm{g} / \mathrm{ml})$ or co-treated with LPS $(5 \mu \mathrm{g} / \mathrm{ml})$ and SK $(100 \mu \mathrm{M})$. After 24-h incubation, the cells were fixed with $4 \%$ paraformaldehyde at $4^{\circ} \mathrm{C}$. The cells were washed with PBS containing 0.1\% BSA and incubated with anti-N-cadherin or anti-E-cadherin antibody for $1 \mathrm{~h}$ followed by 1-h incubation with fluorescence-tagged secondary antibody, then counter-stained with DAPI for $5 \mathrm{~min}$. Cell images were captured at x200 magnification on a Leica fluorescence microscope (Leica, Buffalo Grove, IL, USA).

Statistical analysis. The results are presented as mean \pm SE. Statistical comparisons between groups were carried out using one-way ANOVA followed by the Student's t-test. A P-value $<0.05$ was considered statistically significant.

\section{Results}

Effect of SK on the growth of human breast cancer cells in vitro. We initially examined the effect of SK on the proliferation of the MCF-7 and MDA-MB-231 human breast cancer cell lines. The cells were treated for $24 \mathrm{~h}$ with predetermined concentrations of SK as previously mentioned, and cell viability was measured using the MTT assay. As shown in Fig. 1A, cell proliferation was inhibited by SK in a dose-dependent manner, although a different $\mathrm{IC}_{50}$ (the drug concentration that causes 50\% growth inhibition) was observed for each cell line (12.2 $\pm 0.7 \mu \mathrm{M}$ for MDA-MB-231 and 17.1 $\pm 0.4 \mu \mathrm{M}$ for MCF-7). The long-term effects of SK were determined by culturing MCF-7 and MDA-MB-231 cells with or without SK for 10-15 days, and then performing colony-forming assays. At a concentration of $5 \mu \mathrm{M}$, SK did not show any significant effect, whereas $50 \mu \mathrm{M}$ SK almost completely inhibited colony formation (Fig. 1B). Therefore, we considered $5 \mu \mathrm{M} \mathrm{SK}$ a suitable dose for subsequent experiments.

Effect of SK on the LPS-induced migration of human breast cancer cells. LPS $(5 \mu \mathrm{g} / \mathrm{ml})$ may act as an independent factor to trigger the EMT process, as has previously been reported by Chen and colleagues (13). We investigated the effects of SK on cell migration to verify that SK inhibits the LPS-induced EMT as EMT is associated with enhanced tumor progression. The cancer cell lines were treated with LPS alone, LPS plus SK $(5 \mu \mathrm{M})$, or SK alone $(5 \mu \mathrm{M})$, and wound-healing assays were performed. The LPS-treated cancer cells exhibited a $\geq 1$.7-fold increase in migration, whereas treatment with $5 \mu \mathrm{M}$ SK inhibited this LPS-induced migration by 70 and $40 \%$ for MDA-MB-231 and MCF-7, respectively (Fig. 2A and B). The inhibition of migration was also observed in the SK alone treatment group, where SK decreased the migration by 60 and $30 \%$ for MDA-MB-231 and MCF-7, respectively, compared to the untreated control group. These results showed that SK decreased the migration of cancer cells during EMT by LPS. 

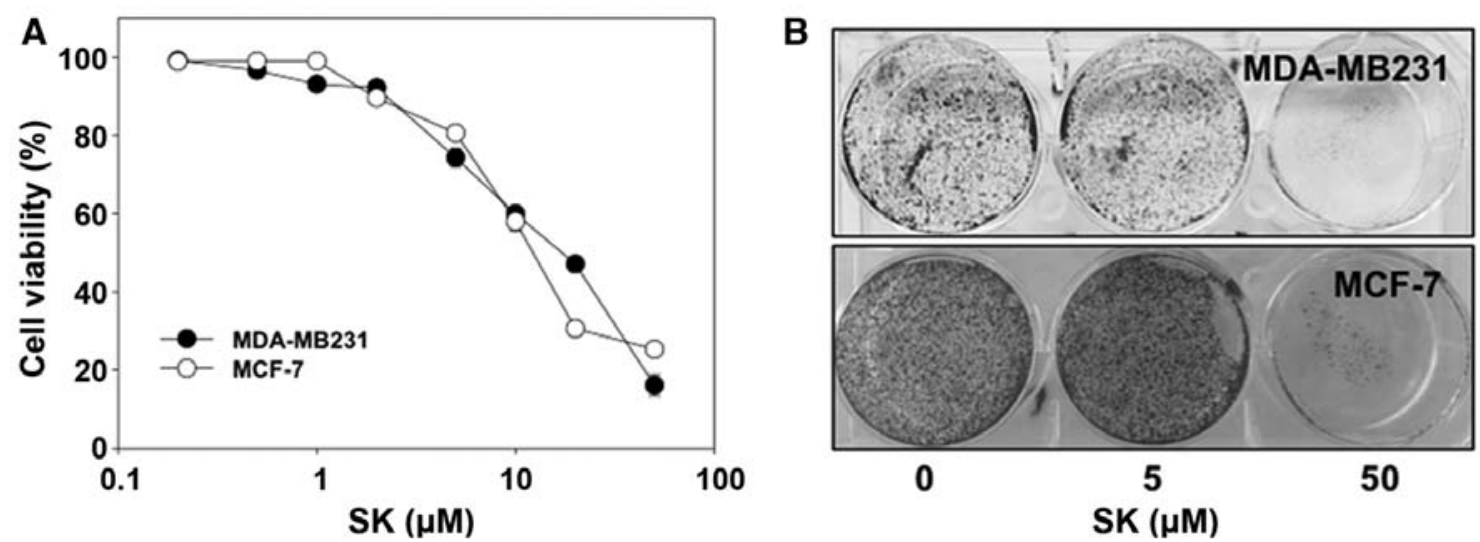

Figure 1. Shikonin (SK) inhibits the growth of human cancer cells. (A) MDA-MB-231 and MCF-7 cells were seeded in a 96-well plate and treated with different concentrations of SK after $24 \mathrm{~h}$. Cell proliferation was determined using the MTT assay. Data are presented as the percentage of proliferation relative to that in the medium-treated controls. The results are expressed as the means \pm SD of three replicate measurements from a single experiment, and are representative of three separate experiments. (B) MDA-MB-231 and MCF-7 cells were seeded in a 6-well plate and treated with 0,5 and $50 \mu$ M SK for 15 days. Colonies were fixed with $100 \%$ methanol for $10 \mathrm{~min}$ at rom temperature and stained with $0.1 \%$ crystal violet. Representative photographs demonstrating colony formation are shown.

\section{A}
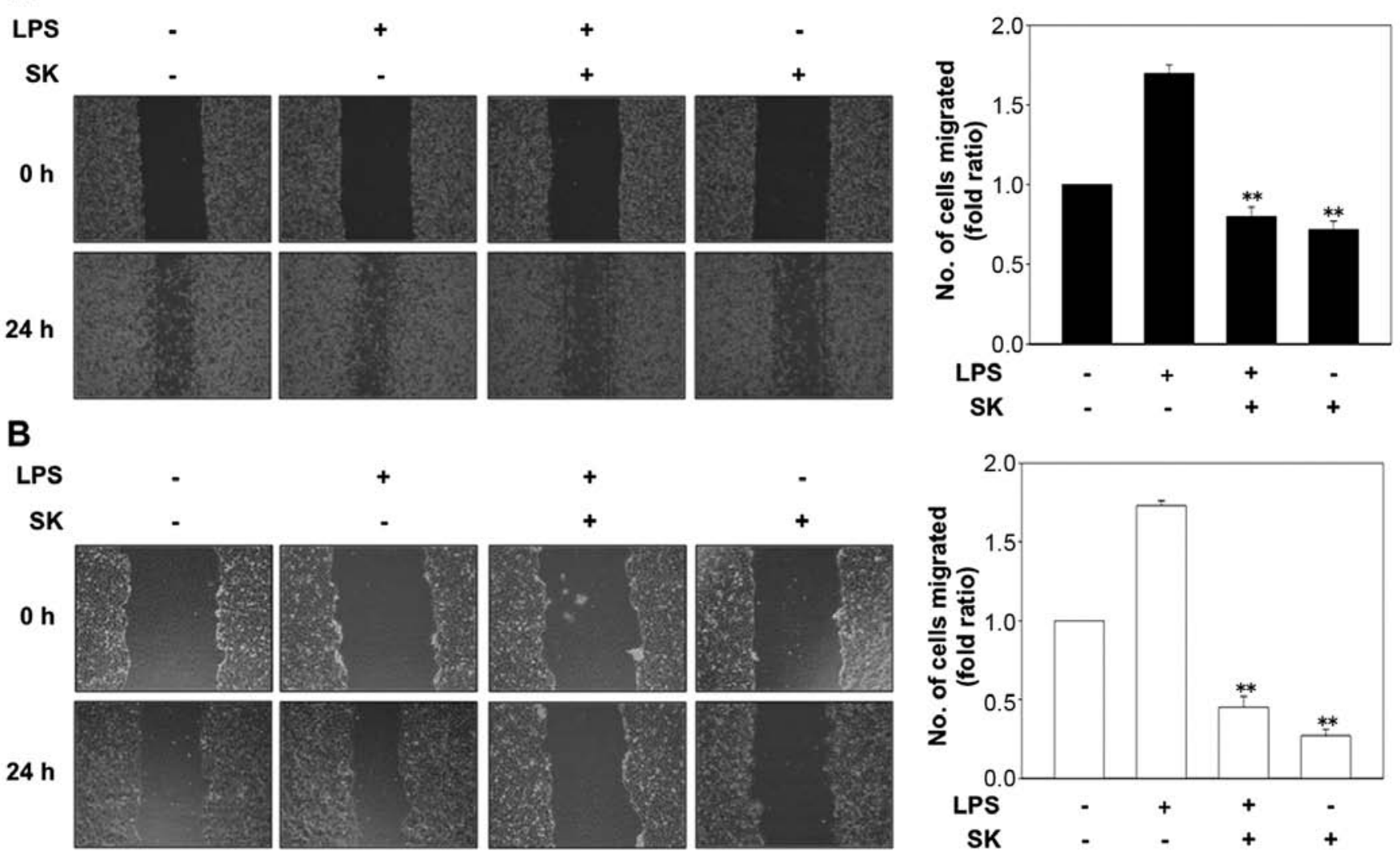

Figure 2. Shikonin (SK) inhibits the LPS-induced cell migration of MDA-MB-231 and MCF-7 cells. (A) MDA-MB-231 and (B) MCF-7 cells were wounded by scratching with a pipette tip and were then incubated with or without $5 \mu \mathrm{g} / \mathrm{ml}$ LPS and SK $(5 \mu \mathrm{M})$. Representative images of wound healing were captured at the time of scratching and $24 \mathrm{~h}$ thereafter. Cell migration into the wounded area was quantified as the fold ratio of wound healing $(\mathrm{n}=5)$. ${ }^{*} \mathrm{P}<0.05,{ }^{* *} \mathrm{P}<0.01 \mathrm{vs}$. LPS-treated cells.

Effect of SK on the LPS-induced invasion of human breast cancer cells. We examined whether SK inhibits the LPS-induced invasiveness of cancer cells. Following treatment with LPS alone, the number of invasive cells significantly increased compared with the untreated cells. However, the number of invasive cells was significantly reduced in the cells treated with the combination of LPS plus SK (Fig. 3A).
The quantitative analysis is shown in Fig. 3B, and the results revealed that SK significantly inhibited the LPS-induced invasion of cancer by 60 and $40 \%$ for MDA-MB-231 and MCF-7, respectively, compared to the untreated control group. These results suggested that SK inhibits the effect of LPS, whereby it increases the invasiveness of human cancer cells, as occurs at the EMT. 
A
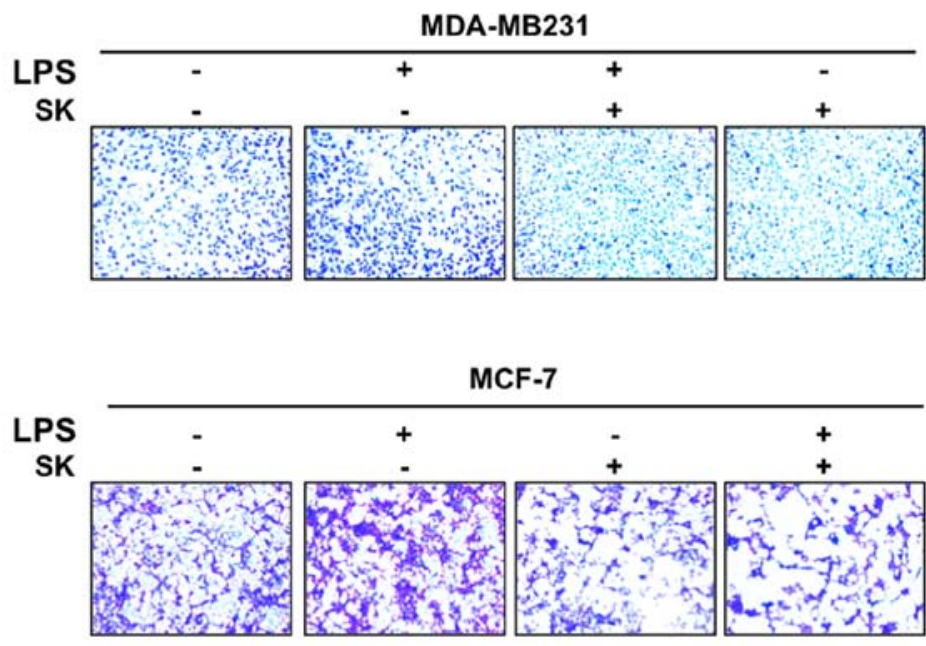

B
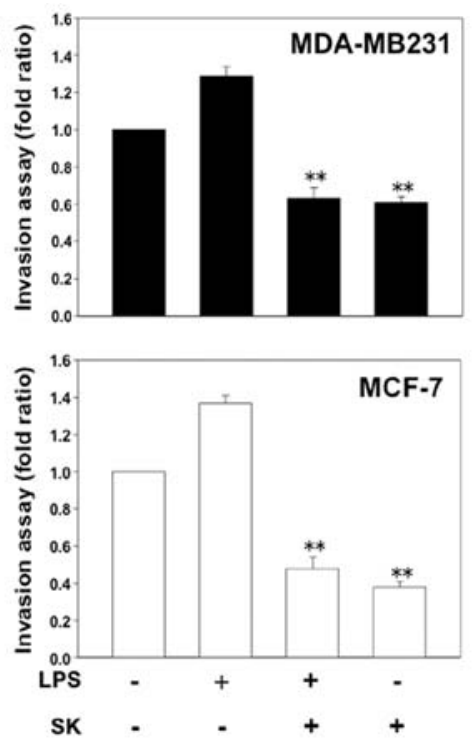

Figure 3. Shikonin (SK) inhibits the cell invasion stimulated by LPS. (A) MDA-MB-231 and MCF-7 cells treated with the SK (5 mM), with or without $5 \mu \mathrm{g} / \mathrm{ml}$ LPS, for $24 \mathrm{~h}$, and invasion was determined by Transwell assays. Representative photomicrographs of membrane-associated cells stained with crystal violet. (B) Cell invasion values were quantified as the fold ratio of invaded cells $(n=5) .{ }^{*} \mathrm{P}<0.05,{ }^{* *} \mathrm{P}<0.01$ vs. LPS-treated cells.

A

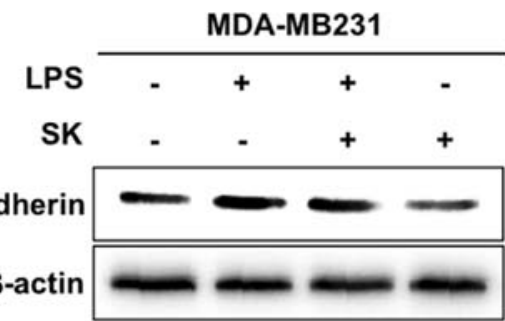

B

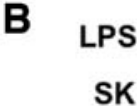

MDA-MB231
(N-cadherin)

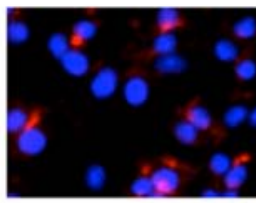

MCF-7

(E-cadherin)
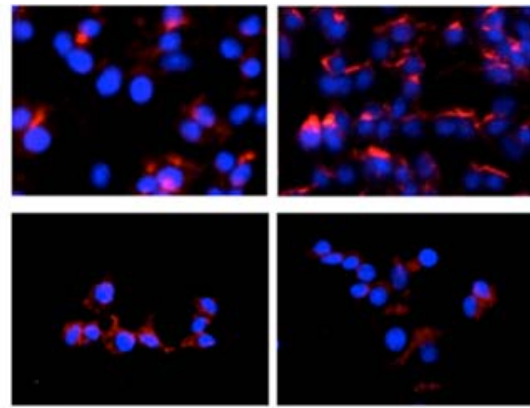

C

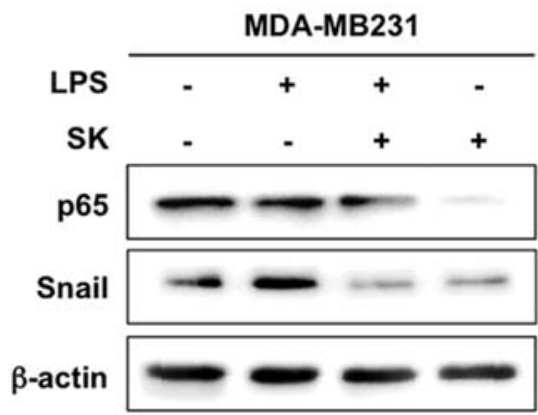

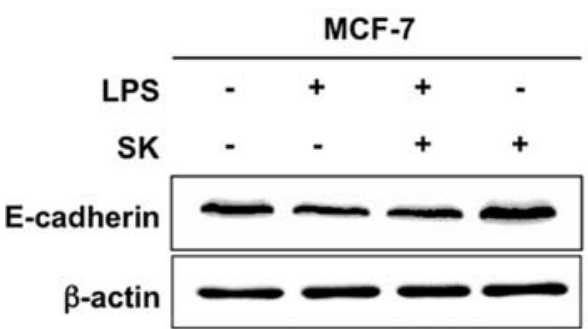
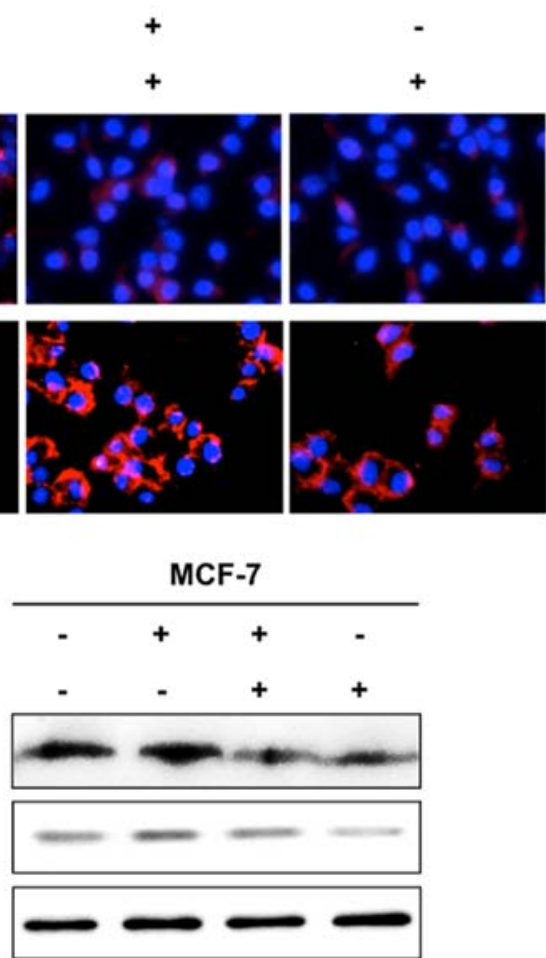

Figure 4. Shikonin (SK) regulates the expression of EMT-associated proteins and inhibits the activation of NF- $\mathrm{BB}$-Snail signaling. (A) Expression of E-cadherin, $\beta$-catenin, N-cadherin, and vimentin proteins in MDA-MB-231 and MCF-7 cells was determined with western blotting. (B) MDA-MB-231 cells were immunostained with anti-N-cadherin antibody and MCF-7 cells were incubated with anti-E-cadherin antibody, and the nuclei were counterstained with 4',6-diamidino-2-phenylindole (DAPI) after SK treatment. (C) Western blot analysis of the expression of the NF-kB p65 subunit and Snail protein in MDA-MB-231 and MCF-7 cells after treatment with SK for $24 \mathrm{~h}$. 
Effect of SK on the expression of EMT-associated proteins. To investigate the effect of SK on LPS-induced EMT, we monitored the expression of the EMT-associated proteins, E- and N-cadherin by western blotting (Fig. 4A). The expression of $\mathrm{N}$-cadherin was significantly upregulated in MDA-MB-231, whereas that of E-cadherin was downregulated in the LPS-treated group compared with their expression in the controls. However, SK reversed the LPS-induced EMT by inhibiting the expression of $\mathrm{N}$-cadherin, and reinducing E-cadherin expression. We also examined N- and E-cadherin expression in cancer cells by immunofluorescence (Fig. 4B). Consistent with the western blotting results, in MDA-MB-231 cells, N-cadherin was highly expressed after LPS treatment, but significantly decreased by the co-treatment with SK. In MCF-7 cells, E-cadherin was seldom expressed after LPS treatment, but significantly recovered by the co-treatment with SK. Taken together, the western blotting and fluorescence imaging results suggested that SK exerts an inhibitory effect on EMT.

$N F-\kappa B$-Snail signaling pathway for reversal of LPS-induced EMT marker expression. It has been previously reported that many drugs may inhibit the invasion and migration of cancer cells by suppressing $\mathrm{NF}-\kappa \mathrm{B}$ activation and Snail induction, suggesting that the $\mathrm{NF}-\kappa \mathrm{B}$ signaling pathway is critically involved in the acquisition of EMT through its downstream target, the transcription factor Snail (18). We investigated the expression of the NF- $\kappa \mathrm{B}$ p65 subunit and Snail protein with western blotting to determine whether the effect of PCAE described above is associated with the inhibition of the NF- $\kappa$ B-Snail pathway. As shown in Fig. 4C, LPS significantly upregulated the expression of $\mathrm{NF}-\kappa \mathrm{B}$ p 65 and Snail protein, which reduced the expression of E-cadherin and increased the expression of N-cadherin. These effects were blunted by SK, suggesting that SK suppresses LPS-triggered EMT by counteracting NF- $\mathrm{B}$ p 65 activation and Snail induction by LPS.

\section{Discussion}

The EMT is the best-known example of the changes that occur in the patterns and functions of cancer cells (19). Epithelial cells acquire mesenchymal fibroblast-like phenotypes, with reduced cell-cell adhesion, loss of polarity, and increased migration and invasiveness (20). The profound changes in cytoskeletal architecture that occur during EMT, together with a reduction in intercellular adhesion and an increase in motility, are fundamental to the metastatic process, enabling these cells to break through the basal membrane and migrate over long distances (21). The EMT is considered to be a significant step in the invasive cascade, facilitating the migration of tumor cells from their site of origin and their dissemination to distant tissues (22). EMT is a complex, stepwise phenomenon that is involved in embryonic development, as well as other physiological and pathological conditions, playing a role in enhancing the invasive and metastatic behavior of cancer cells. Therefore, inhibition of EMT is an attractive therapeutic approach that may have a significant effect on disease outcome.

As previously reported, LPS induces EMT in breast cancer cells, increasing their invasion and migration and resulting in enhanced lung metastasis (23). In the present study, we have shown that breast cancer cells can be induced by LPS to undergo a stimulated EMT, increasing N-cadherin expression in MDA-MB-231, and reducing E-cadherin expression in MCF-7. SK inhibits the action of LPS in inducing the EMT, reversing the altered expression of proteins associated with cell invasion and migration. We also found that NF- $\kappa$ B-SNAIL signaling is required for the LPS-induced EMT in breast cancer cells, which clarifies the mechanism by which SK inhibits cancer cell metastasis.

SK, an active naphthoquinone isolated from the Chinese medicinal herb, Lithospermum erythrorhizon Sieb et Zucc, showed anticancer activity in previous studies (24). Recent findings have shown that SK induces apoptosis, and suppresses cancer cell proliferation (25). However, SK has not been associated with cancer metastasis via the EMT, although its strong antitumor effects have been reported. To the best of our knowledge, this is the first study to demonstrate that the antimetastatic effects of SK are associated with the EMT in cultured human breast cancer cells. Therefore, our results suggest a new chemopreventive role for SK in inhibiting the progression of cancer metastasis.

In the present study, we have shown that SK inhibits the LPS-induced EMT, and thus cell migration and invasion, which result from the dysregulation of cell-cell adhesion proteins and the expression of EMT-associated proteins, such as E- and N-cadherin. Cadherins are transmembrane glycoproteins that mediate $\mathrm{Ca}^{2+}$-dependent cell-cell adhesion (26). E-cadherin is expressed by most epithelial tissues and facilitates tight cell-cell adhesion and suppresses the dissociation of epithelial cells from their locations. The loss of E-cadherin expression correlates with the invasiveness and undifferentiated phenotype of many epithelium-derived cancer cells (27). However, $\mathrm{N}$-cadherin is associated with the heightened invasive potential of cancer cells. N-cadherin is typically expressed by mesenchymal cells, is overexpressed in some cancer cells, and correlates with cell invasiveness (28). Therefore, the loss of E-cadherin expression and the gain of $\mathrm{N}$-cadherin expression in cancer cells have functional significance in cancer progression and metastasis (29).

The results of the present study have also demonstrated that the mechanism of action of SK may involve the suppression of NF- $\kappa \mathrm{B}-$ Snail signaling. NF- $\kappa \mathrm{B}$ is a structurally conserved family of dimeric transcription factors that plays pivotal roles in maintaining an invasive phenotype as well as promoting carcinogenesis (30). It also plays a central role in EMT through direct activation of the transcription of Snail, which has been established as a critical mediator of EMT (31). The expression of Snail mRNA at the EMT may be reversed by the inhibition of $N F-\kappa B$, which is the upstream regulator of SNAIL expression at the EMT (32). Our results support these previous findings and provide a mechanistic basis for the inhibition of tumor progression by SK.

In conclusion, we have demonstrated that SK inhibition of tumor invasion and migration is associated with the EMT process during tumor progression, and is possibly mediated by suppressing NF- $\kappa \mathrm{B}-$ Snail signaling and regulating the expression of $\mathrm{N}$ - and E-cadherin, which are important downstream EMT markers. Although further in vivo studies are required to establish the potential of SK as an anticancer therapeutic agent, we suggest that SK is an effective anticancer agent with antimetastatic activity against breast tumors. 


\section{Acknowledgements}

This study was supported by the Traditional Korean Medicine R\&D program funded by the Ministry of Health and Welfare through the Korea Health Industry Development Institute (HI14C05830000).

\section{References}

1. Jemal A, Siegel R, Ward E, Hao Y, Xu J and Thun MJ: Cancer statistics, 2009. CA Cancer J Clin 59: 225-249, 2009.

2. Parkin DM, Bray F, Ferlay J and Pisani P: Global cancer statistics, 2002. CA Cancer J Clin 55: 74-108, 2005.

3. Coleman RE, Gregory W, Marshall H, Wilson C and Holen I: The metastatic microenvironment of breast cancer: Clinical implications. Breast 22 (Suppl 2): S50-S56, 2013.

4. Sleeman JP, Nazarenko I and Thiele W: Do all roads lead to Rome? Routes to metastasis development. Int J Cancer 128: 2511-2526, 2011.

5. Steeg PS: Tumor metastasis: Mechanistic insights and clinical challenges. Nat Med 12: 895-904, 2006.

6. Gupta GP, Minn AJ, Kang Y, Siegel PM, Serganova I, CordónCardo C, Olshen AB, Gerald WL and Massagué J: Identifying site-specific metastasis genes and functions. Cold Spring Harb Symp Quant Biol 70: 149-158, 2005.

7. Klein CA: Parallel progression of primary tumours and metastases. Nat Rev Cancer 9: 302-312, 2009.

8. Minn AJ, Gupta GP, Siegel PM, Bos PD, Shu W, Giri DD, Viale A, Olshen AB, Gerald WL and Massagué J: Genes that mediate breast cancer metastasis to lung. Nature 436: 518-524, 2005.

9. Kong D, Li Y, Wang Z and Sarkar FH: Cancer stem cells and epithelial-to-mesenchymal transition (EMT)-phenotypic cells: Are they cousins or twins? Cancers (Basel) 3: 716-729, 2011.

10. Polyak K and Weinberg RA: Transitions between epithelial and mesenchymal states: Acquisition of malignant and stem cell traits. Nat Rev Cancer 9: 265-273, 2009.

11. Thiery JP, Acloque H, Huang RY and Nieto MA: Epithelialmesenchymal transitions in development and disease. Cell 139: 871-890, 2009.

12. Yang H, Zhou P, Huang H, Chen D, Ma N, Cui QC, Shen S, Dong W, Zhang X, Lian W, et al: Shikonin exerts antitumor activity via proteasome inhibition and cell death induction in vitro and in vivo. Int J Cancer 124: 2450-2459, 2009.

13. Chen Y, Zheng L, Liu J, Zhou Z, Cao X, Lv X and Chen F: Shikonin inhibits prostate cancer cells metastasis by reducing matrix metalloproteinase-2/-9 expression via AKT/mTOR and ROS/ERK1/2 pathways. Int Immunopharmacol 21: 447-455, 2014.

14. Yeh CC, Kuo HM, Li TM, Lin JP, Yu FS, Lu HF, Chung JG and Yang JS: Shikonin-induced apoptosis involves caspase-3 activity in a human bladder cancer cell line (T24). In Vivo 21: 1011-1019, 2007.

15. Zhang FL, Wang P, Liu YH, Liu LB, Liu XB, Li Z and Xue YX: Topoisomerase I inhibitors, shikonin and topotecan, inhibit growth and induce apoptosis of glioma cells and glioma stem cells. PLoS One 8: e81815, 2013.

16. Fujii N, Yamashita Y, Arima Y, Nagashima M and Nakano H: Induction of topoisomerase II-mediated DNA cleavage by the plant naphthoquinones plumbagin and shikonin. Antimicrob Agents Chemother 36: 2589-2594, 1992.
17. Jang SY, Lee JK, Jang EH, Jeong SY and Kim JH: Shikonin blocks migration and invasion of human breast cancer cells through inhibition of matrix metalloproteinase-9 activation. Oncol Rep 31: 2827-2833, 2014.

18. Wu K and Bonavida B: The activated NF-kappaB-Snail-RKIP circuitry in cancer regulates both the metastatic cascade and resistance to apoptosis by cytotoxic drugs. Crit Rev Immunol 29: 241-254, 2009.

19. Friedl $\mathrm{P}$ and Wolf $\mathrm{K}$ : Tumour-cell invasion and migration: Diversity and escape mechanisms. Nat Rev Cancer 3: 362-374, 2003.

20. De Craene B and Berx G: Regulatory networks defining EMT during cancer initiation and progression. Nat Rev Cancer 13: 97-110, 2013

21. Kalluri R and Weinberg RA: The basics of epithelial-mesenchymal transition. J Clin Invest 119: 1420-1428, 2009.

22. Mulholland DJ, Kobayashi N, Ruscetti M, Zhi A, Tran LM, Huang J, Gleave M and Wu H: Pten loss and RAS/MAPK activation cooperate to promote EMT and metastasis initiated from prostate cancer stem/progenitor cells. Cancer Res 72: 1878-1889, 2012.

23. Wu Y, Deng J, Rychahou PG, Qiu S, Evers BM and Zhou BP: Stabilization of snail by NF-kappaB is required for inflammationinduced cell migration and invasion. Cancer Cell 15: 416-428, 2009.

24. Zhang HJ, Wang HY, Zhang HT, Su JM, Zhu J, Wang HB, Zhou WY, Zhang H, Zhao MC, Zhang L, et al: Transforming growth factor- $\beta 1$ promotes lung adenocarcinoma invasion and metastasis by epithelial-to-mesenchymal transition. Mol Cell Biochem 355: 309-314, 2011.

25. Gara RK, Srivastava VK, Duggal S, Bagga JK, Bhatt M, Sanyal S and Mishra DP: Shikonin selectively induces apoptosis in human prostate cancer cells through the endoplasmic reticulum stress and mitochondrial apoptotic pathway. J Biomed Sci 22: $26,2015$.

26. van Roy F and Berx G: The cell-cell adhesion molecule E-cadherin. Cell Mol Life Sci 65: 3756-3788, 2008.

27. Lombaerts M, van Wezel T, Philippo K, Dierssen JW, Zimmerman RM, Oosting J, van Eijk R, Eilers PH, van de Water B, Cornelisse CJ, et al: E-cadherin transcriptional downregulation by promoter methylation but not mutation is related to epithelial-to-mesenchymal transition in breast cancer cell lines. Br J Cancer 94: 661-671, 2006.

28. Nguyen PT, Kudo Y, Yoshida M, Kamata N, Ogawa I and Takata T: $\mathrm{N}$-cadherin expression is involved in malignant behavior of head and neck cancer in relation to epithelial-mesenchymal transition. Histol Histopathol 26: 147-156, 2011.

29. Araki K, Shimura T, Suzuki H, Tsutsumi S, Wada W, Yajima T, Kobayahi T, Kubo N and Kuwano H: E/N-cadherin switch mediates cancer progression via TGF- $\beta$-induced epithelial-tomesenchymal transition in extrahepatic cholangiocarcinoma. $\mathrm{Br}$ J Cancer 105: 1885-1893, 2011.

30. Ennen M, Klotz R, Touche N, Pinel S, Barbieux C, Besancenot V, Brunner E, Thiebaut D, Jung AC, Ledrappier S, et al: DDB2: A novel regulator of NF- $\kappa \mathrm{B}$ and breast tumor invasion. Cancer Res 73: 5040-5052, 2013.

31. Chua HL, Bhat-Nakshatri P, Clare SE, Morimiya A, Badve S and Nakshatri H: NF-kappaB represses E-cadherin expression and enhances epithelial to mesenchymal transition of mammary epithelial cells: Potential involvement of ZEB-1 and ZEB-2. Oncogene 26: 711-724, 2007.

32. Min C, Eddy SF, Sherr DH and Sonenshein GE: NF-kappaB and epithelial to mesenchymal transition of cancer. J Cell Biochem 104: 733-744, 2008. 